\title{
Direct Costs of Very Old Persons with Subsyndromal Depression: A 5-Year Prospective Study
}

Mikael Ludvigsson, Lars Bernfort, J an Marcusson, Ewa Wressle and Anna Milberg

The self-archived postprint version of this journal article is available at Linköping University Institutional Repository (DiVA):

http:// urn.kb.se/ resolve?urn=urn:nbn:se:liu:diva- 149695

N.B.: When citing this work, cite the original publication.

Ludvigsson, M., Bernfort, L., Marcusson, J ., Wressle, E., Milberg, A., (2018), Direct Costs of Very Old Persons with Subsyndromal Depression: A 5-Year Prospective Study, The American journal of geriatric psychiatry, 26(7), 741-751. https:// doi.org/ 10.1016/j.jagp.2018.03.007

Original publication available at:

https:// doi.org/ 10.1016/j.jagp.2018.03.007

Copyright: Elsevier (12 months)

http:// www.elsevier.com/

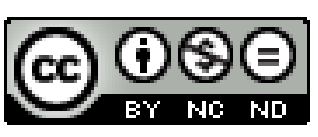




\section{Direct costs of very old persons with subsyndromal depression: a five-year prospective study}

1. Mikael Ludvigsson (MD) ${ }^{1}$

2. Lars Bernfort $(\mathrm{PhD})^{2}$

3. Jan Marcusson (MD, PhD) ${ }^{1}$

4. Ewa Wressle $(\mathrm{PhD})^{1}$

5. Anna Milberg (MD, PhD) ${ }^{3}$

${ }^{1}$ Division of Geriatric Medicine, Department of Clinical and Experimental Medicine, Linköping University, Linköping, Sweden.

${ }^{2}$ Division of Health Care Analysis, Department of Medical and Health Sciences, Linköping University, Linköping, Sweden.

${ }^{3}$ Palliative Education \& Research Centre, Linköping University, Norrköping, Sweden, Department of Advanced Home Care and Department of Social and Welfare Studies, Linköping University, Norrköping, Sweden

Corresponding author: Mikael Ludvigsson

- E-mail: mikael.ludvigsson@regionostergotland.se

- Address: Psykosmottagningen, plan 10, ingång 27; Universitetssjukhuset I Linköping; 58185 Linköping, Sweden. Fax number: +46-10-103 3894; Telephone: +46-76-843 8473

Key words: Subthreshold depression, multimorbidity, oldest old, elderly, cost-of-illness, latelife depression

\section{Declaration of interest}

No Disclosures to Report

\section{Role of the funding source}

This project was supported by grants from the County Council of Östergötland, Sweden. The funding source had no involvement in the study design, data collection, analysis, interpretation of the data nor in writing the manuscript. 


\section{Contributors}

All authors contributed to the design of the study. Mikael Ludvigsson, Ewa Wressle and Jan Marcusson collected the data. Mikael Ludvigsson managed the literature searches and analyses. Mikael Ludvigsson and Anna Milberg undertook the statistical analyses and wrote the first draft of the manuscript. All authors contributed to and have approved the final manuscript.

\section{Acknowledgements}

We thank Mr Mats Fredriksson at Forum Östergötland, Linköping University, for help with the statistical analyses. We thank Mr Rolf Wiklund at the County Council of Östergötland and Mr Johan Eriksson at the Municipal offices of Linköping, who both kindly provided cost data for our analyses.

\section{Abstract}

Objectives: This study aimed to compare, over a five-year period, the prospective direct healthcare costs and service utilization of persons with subsyndromal depression (SSD) and non-depressive persons (ND), in a population of very old persons. A second aim was to develop a model that predicts direct healthcare costs in very old persons with SSD.

Design and setting: A prospective population-based study was undertaken on 85-year-old persons in Sweden.

Measurements: Depressiveness was screened with GDS-15 (Geriatric Depression Scale) at baseline and at one-year follow-up, and the results were classified into ND, SSD and syndromal depression. Data on individual healthcare costs and service use from a five-year period were derived from national database registers. Direct costs were compared between categories using Mann-Whitney U-tests, and a prediction model was identified with linear regression.

Results: For persons with SSD, the direct healthcare costs per month of survival exceeded those of persons with ND by a ratio 1.45 (€634 vs $€ 436$ ), a difference that was significant even after controlling for somatic multimorbidity. The final regression model consisted of five independent variables predicting direct healthcare costs: male sex, ADL functions, loneliness, presence of SSD, and somatic multimorbidity.

Conclusions: SSD among very old persons is associated with increased direct healthcare costs independently of somatic multimorbidity. The associations between SSD, somatic multimorbidity and healthcare costs in the very old need to be analysed further in order to better guide allocation of resources in health policy.

Keywords: Subthreshold depression, multimorbidity, oldest old, elderly, cost-of-illness, latelife depression 


\section{Manuscript}

\section{Objective}

Depression is one of the most prevalent disorders in late life, and by 2030 it is projected to be the major contributor to disease burden in high-income countries (2). During the last 15 years a growing body of literature has dealt with subsyndromal depression (SSD) or subthreshold depression, i.e. depressiveness below the threshold of what is called a syndromal depressive episode $(3,4)$. Even though the degree of functional impairment and suffering is relatively smaller in patients with subsyndromal depression than in those with syndromal depression, the number of persons affected is much larger, with prevalence rates ranging from $3.6 \%$ to $35.9 \%$ in primary care and from $4.0 \%$ to $22.9 \%$ in community settings (5) .

Previous studies have shown that elderly persons with depression have higher direct healthcare costs than do other elderly persons (6). In addition, SSD in persons of age 60 and over is associated with higher healthcare costs than average $(7,8)$. Studies on very old persons are valuable as the very old (80+ years) differ in general from the young old (60-80 years) in respects such as degree of multimorbidity, frailty and social dependence. The healthcare costs of the very old with multimorbidity and frailty have been investigated (9). Two papers have focused on costs of depression in the very old $(10,11)$, and one paper have investigated impact of depressive symptoms in general on healthcare costs in the very old (12)

However, to our knowledge no studies have investigated whether very old persons with SSD have higher direct costs than average for their age group. With the help of such knowledge, the planning of health care could improve, which is especially important in the context of the worldwide demographic development of a gradual increase in the proportion of very old persons.

The aim of the present study was to provide a comparison between the prospective direct healthcare costs and service utilization for persons with SSD compared with non-depressive persons in a Swedish population of very old persons over a five-year period. A second aim was to develop a model that predicts direct healthcare costs in very old persons with SSD. Based on previous literature on persons of lower ages we hypothesized that direct costs of very old persons with SSD would be higher than for non-depressive persons, independent of somatic multimorbidity, and that the factors of somatic multimorbidity, cognitive dysfunction (13), physical functioning and impaired activities of daily living (ADL) (14), chronic pain (15), and loneliness (16) would also predict increased direct costs.

\section{Methods}

\subsection{Sample}

Data were obtained from the prospective observational cohort study "Elderly in Linköping Screening Assessment" (ELSA 85), with a population-based design of 85-year-old persons in the south of Sweden (17). All persons born in 1922 and living in Linköping municipality in Sweden $(n=650)$ in 2007 were invited to participate (Figure 1), and no exclusion criteria were 
used. The present study was approved by the Research Ethics Committee of Linköping University, Sweden (141-06).

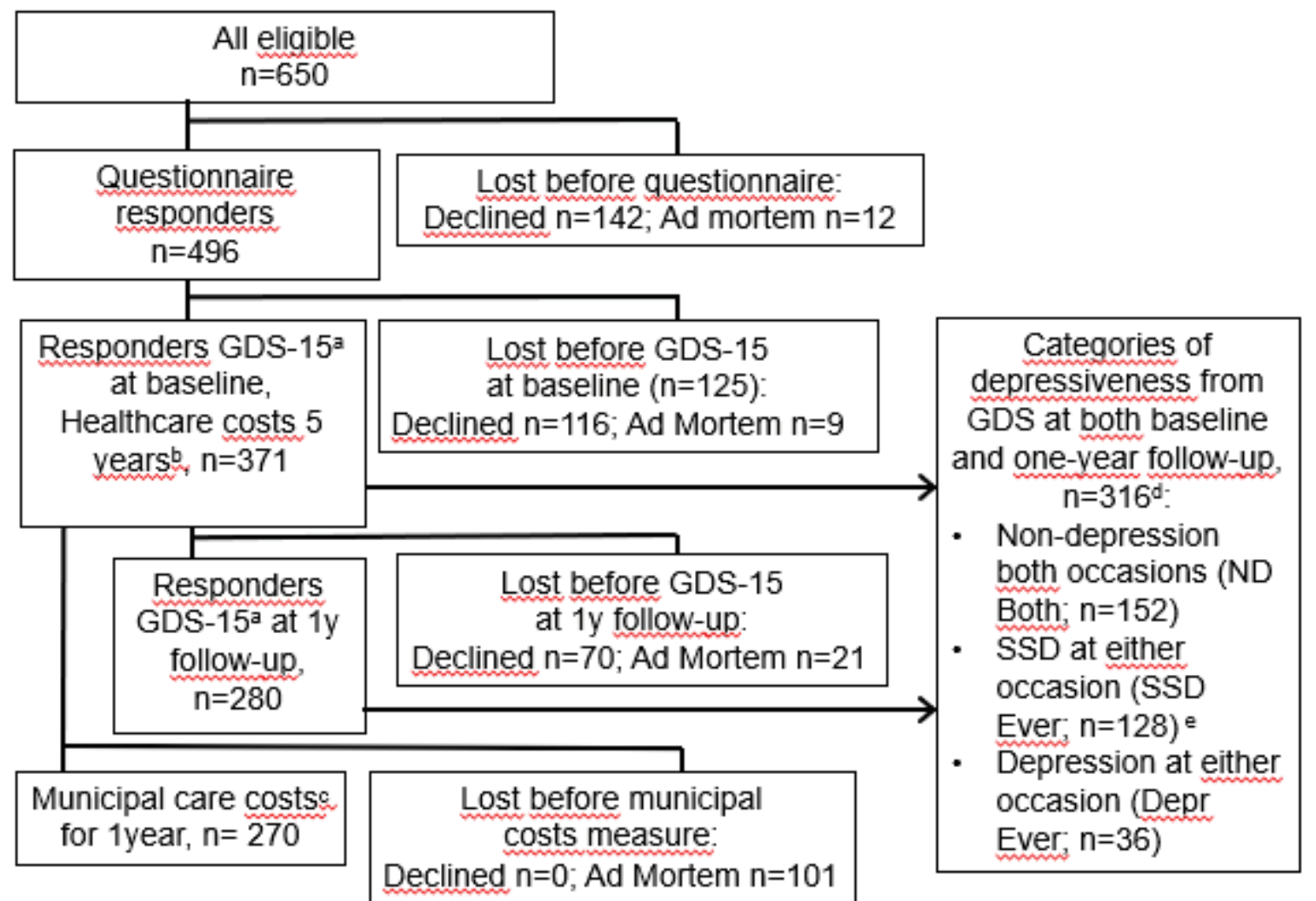

Figure 1. Derivation of the analytical samples from the ELSA-85 study. Notes: a GDS-15 assessment through interview at a home visit. ${ }^{b}$ The 5 prospective years per individual from baseline 2007-2008 according to birth date. ' Municipal data collected between 4 and 5 years after baseline, during 2011-12. ${ }^{d}$ The difference between the analytical sample $n=316$ and the responders at baseline $n=371$ consisted of individuals $(n=55)$ with ND at baseline and who declined before one-year follow-up. eSixteen individuals corresponded to both the categories SSD Ever and Depr Ever, but for the calculations of the study these persons vere excluded from the category of SSD Ever, in order to better distinguish the effects per category.

\subsection{Setting}

The municipality of Linköping is a city with about 150000 inhabitants in the southeast of Sweden. The age distribution is similar to the rest of the country, with almost $20 \%$ of the people over 65 years of age, and about $5 \%$ over 80 years. In Sweden, public resources are state controlled. Provisions for community services and healthcare are mainly funded by taxes and are universally available according to individual needs (18). Individuals pay a fee (€1530) for a visit to a general practitioner in primary care, or for a visit to secondary care or emergency room. For a hospital stay the fee per day is about a third of the price (€5-10). Most of Sweden's elderly residents live in private homes. For those requiring care at home, municipalities offer actual care services. These are managed either directly by the municipalities or indirectly by private care companies. 


\subsection{Measures}

\subsubsection{Categories of depressiveness}

Depressiveness was operationalized in three categories: non-depression (ND), SSD and syndromal depression. In this study, we chose to define SSD and syndromal depression on the basis of the results from GDS-15 (19). GDS-15 is a valid and reliable self-report screening instrument assessing depressive symptoms in older people, and it contains 15 questions with yes/no-answers and one point for each question (20). In our study, $0-2 p$ were interpreted as $\mathrm{ND}, 3-5 \mathrm{p}$ were interpreted as SSD, and $\geq 6 \mathrm{p}$ were interpreted as syndromal depression. This cut-off value for syndromal depression is common, while the cut-off between ND and SSD is more variable between studies (21). In order to increase validity of the categories of depressiveness the GDS-15 was measured both at baseline and at one-year follow-up, as affective disorders vary in intensity over time (22). On the basis of these two measurements the subjects were divided into the categories 1) presence of non-depression at both baseline and follow-up (ND Both), 2) presence of SSD at either baseline or follow-up (SSD Ever), 3) and presence of depression at either baseline or follow-up (Depr Ever).

\subsubsection{Healthcare utilization}

Data on health care utilization were derived from the population-based administrative healthcare register care data warehouse in Östergötland (CDWÖ), containing data from both public care, and from the vast majority of private care services in the region (23).

\subsubsection{Costs for healthcare and municipal care}

Data on public healthcare costs were derived from the national database Cost Per Patient (CPP) via the county council of Östergötland, Sweden (24). Since 2005, the CPP database has been available with data on costs for each patient utilizing the healthcare system. Standard costs for different care components, e.g. a specific examination or a surgical procedure, are used to calculate CPP. The standard costs for different care components are thereafter attributed to a specific healthcare contact (derived from the CDWÖ) and summarized to CPP. Other costs, i.e. overhead costs and costs not attributed to specific healthcare contacts are distributed on individual CPP contacts.

Data on municipal costs for elderly care were derived from the database Cost Per User (CPU). The principles for calculating CPU are the same as for the database CPP above, though the municipal costs instead of healthcare correspond to costs for living at nursing homes, transportation services, domestic care services, as well as ordered meals. As the registration to the CPU database started in 2010 for the municipality, not until 2011 was the quality of data judged sufficient for this study, with the consequence that the municipal costs were only available for 270 of the 371 participants still living by the year 2011. All costs were calculated using price lists for each year, and presented as costs per month of survival as many of the participants died during the five-year study period. The costs were also transformed to price levels of September 2016 using the Consumer Price Index, and transformed to EURO $(€)$ in order to facilitate comparison with other studies. Following the guidelines of the Swedish Council on Health Technology Assessment (SBU) we used a discount rate of three percent. The data collection through substantial public data registers allowed a detailed naturalistic and comprehensive assessment of healthcare costs for each 
individual and eliminated the recall bias that has been a relevant limitation in previous health economic studies of the study field (6).

\subsubsection{Other independent variables}

The statistical models included baseline characteristics such as the covariates sex, type of accommodation, household living arrangement and educational level. Somatic multimorbidity or multiple coexisting chronic diseases, were operationalized as the number of chronic diseases out of a predetermined list of 12 disease categories (25): arrhythmic heart disease, chronic heart failure or myocardial infarction, other vascular disease, hypertension or hyperlipidemia, diabetes mellitus, thyroid disease, respiratory disease, joint disease, central nervous system disease, gastrointestinal disease, urinary incontinence, and malignancy.

Overall cognitive function was assessed at the home visit using the MMSE (26), and results $<25 \mathrm{p}$ of the maximum $30 \mathrm{p}$ were regarded as cognitive dysfunction in this study (27). Physical function was operationalized as the use of mobility assistive devices (yes/no). Lower $A D L$ functions were measured through self-report in the item EQ-5D Usual activities (some or severe problems), and presence of pain was measured similarly through the item EQ-5D Pain/discomfort (moderate of extreme pain) from the EQ-5D instrument (28). Loneliness was measured with a single item question constructed by the authors about feelings of loneliness on a four-level scale of frequency: often, sometimes, seldom or never (29).

\subsection{Statistical analyses}

The SPSS Statistical package (version 23.0) was used for the data analyses. Differences in characteristics between participants (who responded to GDS at baseline; $n=371$ ) and nonparticipants (who responded to the initial questionnaire but not to GDS, $n=125$ ) were investigated using $\chi^{2}$-tests and two-sided $t$-tests. As often in healthcare expenditures the costs and service utilization data of the study had a positively skewed non-normal distribution, why comparisons of costs were done with Mann-Whitney U-tests, and log transformation of cost values was done before performing linear regressions with calculation of unstandardized Bcoefficients, 95\% confidence intervals (CI) and p-values. Adjustment for multiple comparisons was done for costs and service use separately with the False Discovery Rate method (1). Correlation matrices were calculated to identify significant intercorrelation between variables, but no variables had to be excluded for this reason. All the hypothesized independent variables and the sociodemographic variables of sex and educational level were selected for the multivariate regression, using backward stepwise automatic model selection to identify an adequate final multivariate regression model with log total healthcare costs as the dependent variable. The number of missing values among the participants was generally small, ranging from 0 to $5 \%$ (18/371 on the MMSE cognitive test), and missing values were excluded listwise for the analyses. The level of significance was set to $\alpha=0.05$.

\section{Results}

\subsection{Sample characteristics}

Figure 1 shows the derivation of the analytical sample of $n=316$ individuals, even though some descriptive data also is presented in the following for all the $n=371$ who responded to 
the GDS-15 at baseline. An overview of sample characteristics at baseline for the categories of depressiveness that were used in the further analysis is presented in Table 1. For the participants there was a general pattern of higher proportions of declining functioning variables associated with a higher degree of depressiveness, which also corresponded to higher numbers of chronic diseases and shorter survival time, while the proportions of educational level and sex did not differ significantly across categories of depressiveness.

Table 1. Sample characteristics at baseline (age 85 ) for the $n=316$. The responders were divided into the categories ND Both (GDS 0-2p at both baseline and one-year follow-up), SSD Ever (GDS 3-5p at either baseline or follow-up) and Depr Ever (GDS $\geq 6 p$ at either baseline or follow-up) for further statistical analyses

\begin{tabular}{|c|c|c|c|}
\hline 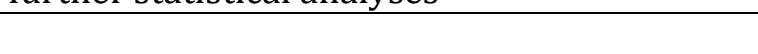 & ND Both $(n=152)$ & SSD Ever $(n=128)$ & Depr Ever $(n=36)$ \\
\hline Male sex, n (\%) & $71(46.7)$ & $46(35.9)$ & $12(33.3)$ \\
\hline Adapted housinga, n (\%) & $1(0.7)$ & $19(14.8)$ & $8(22.2)$ \\
\hline Living alone, $\mathrm{n}(\%)$ & $80(52.6)$ & $73(57.0)$ & $26(72.2)$ \\
\hline Low level of education (<9 years), $n(\%)$ & $97(63.8)$ & $83(64.8)$ & $27(75.0)$ \\
\hline Loneliness, sometimes or often, $n$ (\%) & $37(24.6)$ & $56(45.2)$ & $29(82.8)$ \\
\hline Use of mobility assistive devices $n(\%)$ & $44(28.9)$ & $87(68.0)$ & $29(80.6)$ \\
\hline Lower ADL functions, some or severe problems $n(\%)$ & $9(5.9)$ & $47(36.7)$ & $23(63.9)$ \\
\hline Pain/ Discomfort (EQ-5D), moderate or extreme n(\%) & $95(62.5)$ & $92(71.9)$ & $31(86.1)$ \\
\hline Cognitive dysfunction (MMSE<25p) n(\%) & $7(4.6)$ & $31(24.2)$ & $10(27.8)$ \\
\hline Number of chronic somatic diseases, mean (SD) & $2.2(1.4)$ & $2.8(1.6)$ & $3.2(1.9)$ \\
\hline Number of months of survival from baseline, mean (SD) & $57(9.0)$ & $49(16)$ & $50(16)$ \\
\hline
\end{tabular}

${ }^{a}$ Adapted housing: i.e. sheltered housing, nursing home or dementia care

Comparisons with the $X^{2}$-test between those who responded to GDS ( $n=371$; figure 1 ) at baseline and those who responded to the preceding postal questionnaire but not to GDS $(n=125)$ revealed that a significantly lower proportion of GDS responders were of female gender, living in adapted housing, and had lower ADL functions.

\subsection{Direct costs}

Table 2 shows the distribution of healthcare and municipal costs, as well as healthcare service use across the different categories of depressiveness. Mean total healthcare costs per month for the whole sample amounted to $€ 608( \pm 628)$ per capita which, when extrapolated to annual costs, was $€ 7301$ ( \pm 7539$)$. Inpatient care accounted for almost half of the total healthcare costs, while primary and secondary outpatient care accounted for similar proportions of the rest. Private healthcare costs were only about ten percent, and pharmaceutical costs about $15 \%$ of the public healthcare costs.

Table 2. Comparison with Mann-Whitney U-tests of prospective healthcare direct costs and service use between the categories ND Both, SSD Ever and Depr Ever 


\begin{tabular}{|c|c|c|c|c|c|c|c|c|}
\hline & & & $\begin{array}{l}\text { NDBoth } \\
(n=152)\end{array}$ & $\begin{array}{l}\text { SSDEver } \\
(n=128)\end{array}$ & $\begin{array}{l}\text { DeprEver } \\
(n=36)\end{array}$ & $\begin{array}{c}\text { All } \\
(n=316)\end{array}$ & $\begin{array}{l}\text { p-value (U- } \\
\text { test), a, b SSD } \\
\text { Ever vs ND } \\
\text { Both }\end{array}$ & $\begin{array}{l}\text { p-value (U- } \\
\text { test), a, b } \\
\text { Depr Ever vs } \\
\text { ND both }\end{array}$ \\
\hline \multirow{7}{*}{$\begin{array}{l}\text { Healthcare } \\
\text { direct costs } \\
\text { per capita } \\
\text { monthly }(€)^{\mathrm{c}}\end{array}$} & $\begin{array}{c}\text { Total } \\
\text { Healthcare } \\
\text { costs, mean } \\
\text { (SD) }\end{array}$ & & $436(367)^{d}$ & $634(611)^{d}$ & $693(759)$ & $545(539)^{e}$ & 0.048 & 0.018 \\
\hline & $\begin{array}{l}\text { Inpatient care, } \\
\text { mean (SD) }\end{array}$ & & $171(234)$ & $290(396)$ & $280(336)$ & $224(319)^{f}$ & 0.014 & 0.068 \\
\hline & Outpatient care & $\begin{array}{c}\text { Primary care, } \\
\text { mean (SD) }\end{array}$ & $148(104)$ & 197 (189) & $348(591)$ & $184(239)^{f}$ & 0.005 & 0.003 \\
\hline & & $\begin{array}{c}\text { Secondary } \\
\text { outpatient care, } \\
\text { mean (SD) }\end{array}$ & $141(220)$ & $149(206)$ & $106(81)$ & $136(196)^{f}$ & 0.311 & 0.707 \\
\hline & $\begin{array}{l}\text { Pharmaceutical } \\
\mathrm{s}, \mathrm{g} \text { mean (SD) }\end{array}$ & & $67(107)$ & $82(69)$ & $83(51)$ & $77(90)$ & 0.005 & 0.113 \\
\hline & $\begin{array}{l}\text { Non- } \\
\text { pharmaceutical } \\
\text { components, } \mathrm{g} \\
\text { mean (SD) }\end{array}$ & & $343(330)$ & $516(543)$ & $525(449)$ & $446(467)$ & 0.005 & 0.013 \\
\hline & $\begin{array}{c}\text { Private } \\
\text { healthcare, } \\
\text { mean }(S D)\end{array}$ & & $49(77)$ & $40(90)$ & $126(571)$ & $56(208)$ & 0.048 & 0.675 \\
\hline \multirow{2}{*}{$\begin{array}{l}\text { Municipal } \\
\text { care direct } \\
\text { costs per } \\
\text { capita } \\
\text { monthly }(€)^{i}\end{array}$} & $\begin{array}{l}\text { Total costs, } \\
\text { mean (SD) }\end{array}$ & & $402(1078)$ & 975 (1398) & $2298(1593)$ & 820 (1411) & 0.005 & 0.003 \\
\hline & $\begin{array}{c}\text { Adapted } \\
\text { housing, }{ }^{j} \text { mean } \\
\text { (SD) }\end{array}$ & & $37(166)$ & $109(248)$ & $225(277)$ & $90(246)$ & 0.005 & 0.003 \\
\hline \multirow{8}{*}{$\begin{array}{l}\text { Healthcare } \\
\text { service use } \\
\text { per capita } \\
\text { monthly }\end{array}$} & $\begin{array}{c}\text { Total } \mathrm{n} \\
\text { healthcare } \\
\text { visits, mean } \\
\text { (SD) }\end{array}$ & & $1.6(1.5)$ & $1.8(3.1)$ & $2.8(7.4)$ & $1,8(3,3)^{k}$ & 0.620 & 0.469 \\
\hline & $\begin{array}{l}\mathrm{N} \text { visits to a } \\
\text { physician in all,, } \\
\text { mean (SD) }\end{array}$ & & $0.50(0.38)$ & $0.48(0.56)$ & $0.74(2.2)$ & $0.52(0.87)$ & 0.240 & 0.364 \\
\hline & Inpatient care & $\begin{array}{l}\text { All inpatient } \\
\text { care, } \mathrm{n} \\
\text { occasions; } \\
\text { mean (SD) }\end{array}$ & $\begin{array}{l}1.9 * 10^{-2} \\
\left(3.6 * 10^{-2}\right)\end{array}$ & $\begin{array}{c}1.4 * 10^{-2} \\
\left(3.8 * 10^{-2}\right)\end{array}$ & $\begin{array}{c}2.3^{*} 10^{-2} \\
\left(6.4^{*} 10^{-2}\right)\end{array}$ & $\begin{array}{c}1.7 * 10^{-2} \\
\left(4.0 * 10^{-2}\right)\end{array}$ & 0.104 & 0.626 \\
\hline & & $\begin{array}{c}\text { Specific } \\
\text { psychiatric } \\
\text { inpatient care, } \\
\text { n occasions; }^{m} \\
\text { mean (SD) }\end{array}$ & $\begin{array}{c}1.0 * 10^{-4} \\
\left(1.4 * 10^{-3}\right)\end{array}$ & $0.00(0.00)$ & $0.00(0.0)$ & $\begin{array}{l}1.0^{*} 10^{-4} \\
\left(9.4 * 10^{-4}\right)\end{array}$ & 0.620 & 0.626 \\
\hline & Outpatient care & $\begin{array}{l}\text { Primary care } \mathrm{n} \\
\text { visits; mean } \\
\text { (SD) }\end{array}$ & $1.3(1.3)$ & $1.5(3.0)$ & $2.6(7.3)$ & $1.5(3.2)$ & 0.670 & 0.626 \\
\hline & & $\begin{array}{l}\text { Emergency } \\
\text { room, n visits; } \\
\text { mean (SD) }\end{array}$ & $\begin{array}{c}3.9 * 10^{-2} \\
\left(4.6 * 10^{-2}\right)\end{array}$ & $\begin{array}{c}4.8^{*} 10^{-2} \\
\left(7.0^{*} 10^{-2}\right)\end{array}$ & $\begin{array}{c}3.5^{*} 10^{-2} \\
\left(4.5^{*} 10^{-2}\right)\end{array}$ & $\begin{array}{c}4.2 * 10^{-2} \\
\left(5.7 * 10^{-2}\right)\end{array}$ & 0.690 & 0.626 \\
\hline & & $\begin{array}{l}\text { All secondary } \\
\text { outpatient care, } \\
\mathrm{n} \text { visits; mean } \\
\text { (SD) }\end{array}$ & $0.31(0.37)$ & $0.30(0.71)$ & $0.15(0.17)$ & $0.28(0.53)$ & 0.104 & 0.008 \\
\hline & & $\begin{array}{c}\text { Specific } \\
\text { psychiatric } \\
\text { outpatient care, } \\
\text { n visits; }{ }^{\mathrm{m}} \text { mean } \\
\text { (SD) }\end{array}$ & $\begin{array}{c}1.0^{*} 10^{-2} \\
\left(1.2 * 10^{-2}\right)\end{array}$ & $\begin{array}{c}1.6 * 10^{-3} \\
\left(1.6 * 10^{-2}\right)\end{array}$ & $0.00(0.00)$ & $\begin{array}{l}1.7 * 10^{-2} \\
\left(2.2 * 10^{-2}\right)\end{array}$ & 0.620 & 0.626 \\
\hline
\end{tabular}


$\mathrm{a}=$ Correction for multiple comparisons with help of the method False Discovery Rate according to Benjamini and Hochberg (Benjamini 2010) via calculator online at SDM project web

(https:/www.sdmproject.com/utilities/?show=FDR; the 23 ${ }^{\text {rd }}$ of January, 2018; Neuroimaging software library). These calculations were done separately for costs and healthcare service use.

$\mathrm{b}=\mathrm{df}$ for the Mann-Whitney U-tests were equal to the smallest group size of the comparison, i. e. $\mathrm{df} 128$ ( $\mathrm{n}=128$ for SSD Ever) in the comparison between SSD Ever vs ND Both, and df 36 ( $n=36$ for Depr Ever) in the comparison between Depr Ever vs ND Both.

$\mathrm{c}=$ Adjusted for the number of months of survival

$\mathrm{d}=$ The ratio between the mean values for SSD Ever/ND Both was 1.45, while the corresponding ratio between the median values was 1.48. Median total healthcare costs was $€ 433$ (q1=211, q3=842) for SSD Ever and $€ 293$ $(q 1=190, q 3=579)$ for ND Both. Sensitivity analyses with varying discount rates did not change the ratio between the mean values.

$\mathrm{e}=$ The mean total healthcare cost was $€ 608( \pm 628)$ for the whole sample of $n=371$, and $€ 545( \pm 539)$ for the smaller sample of $n=316$. The median total healthcare cost for the whole sample of $n=371$ was $€ 412(q 1=216$, $\mathrm{q} 3=781)$, instead of the median $€ 371(\mathrm{q} 1=201, \mathrm{q} 3=718)$ for the $\mathrm{n}=316$. In sensitivity analyses the mean value for the whole sample of $n=371$ was $€ 645( \pm 666)$ at $0 \%$ discount rate, and $€ 586( \pm 605)$ at $5 \%$ discount rate.

$\mathrm{f}=$ Compared to the numbers for the $\mathrm{n}=316$ individuals of the table, the mean total costs for the whole sample $\mathrm{n}=371$ were $€ 267( \pm 381)$ for inpatient care, $€ 191( \pm 250)$ for primary outpatient care, and $€ 149( \pm 230)$ for secondary outpatient care.

$\mathrm{g}=$ These numbers were only built on public costs data

$\mathrm{h}=$ Only $\mathrm{n}=160$ had any private healthcare during the study period.

$\mathrm{i}=$ Municipal costs were built only on data from a one year period between 2011-12, and those still surviving by the time $n=242$, of which $n=134$ (ND+ND), n=82(SSD Ever) and $n=26$ (Depr Ever).

$\mathrm{j}=$ Only $\mathrm{n}=38$ of the 242 individuals with municipal costs lived in adapted housing

$\mathrm{k}=$ The mean number of healthcare visits was $1.8( \pm 3.2)$ for the whole sample of $\mathrm{n}=371$, and $1.8( \pm 3.3)$ for the smaller sample of $n=316$. The median total number of healthcare visits for the whole sample of $n=371$ was 1.0 $(q 1=0.42, q 3=2.1)$, instead of the median $1.2(q 1=0.52, q 3=2.3)$ for the $n=316$.

$1=$ Number of visits to a physician is only based on data from four years of the study period

$\mathrm{m}=$ There were only 1 psychiatric inpatient occasion, and only 31 psychiatric outpatient visits of the total 28626 visits for all the 371 persons during the five-year study period.

$\mathrm{n}=$ Visits at the emergency room was only to a physician

Despite the fact that only $16 \%$ of the persons had adapted housing (as a major cost component) by the time municipal costs were measured, still the mean total municipal costs were clearly higher than the mean total healthcare costs per capita.

For persons with SSD Ever, both healthcare costs in general and municipal costs were significantly higher than for persons with ND Both, even though such differences were not significant for the sector of outpatient secondary care. Comparing mean total costs, individuals with SSD Ever exceeded those with ND Both by a ratio of 1.45 (€634 vs €436) in mean total healthcare costs, and by a factor of 2.43 (€975 vs €402) in mean total municipal costs. Similar patterns were seen for persons with Depression Ever compared with ND Both, although no significant differences were seen for the components private care or inpatient care. Those individuals with the highest total healthcare costs consisted of somatically multimorbid patients with a high amount of inpatient care.

\subsection{Healthcare service use}

The mean number of healthcare visits in total was $1.8( \pm 3.2)$ per month or $21.0( \pm 38.2)$ per year and per capita for the whole sample (table 2). Only three persons had any contact at all with secondary psychiatric care during the study period, and the number of visits to secondary psychiatric care altogether corresponded to only 0.1 percent of all healthcare contacts in five years. 
In contrast to the above mentioned differences in direct costs between the categories of depressiveness, the only significant difference in service use was that persons with ND Both had more visits to secondary outpatient care than those with Depr Ever.

\subsection{Linear regression analyses with log healthcare costs as dependent variable}

Through univariate analyses three factors were identified that had a significant association with the dependent variable log value of direct healthcare costs (table 3): presence of SSD, loneliness, and somatic multimorbidity. In the subsequent multivariate linear regressions were built a final model of five independent variables significantly predicting direct healthcare costs: male sex, ADL functions, loneliness, presence of SSD, and somatic multimorbidity. However, the predictive values of the multivariate model as a whole were low, indicating that other factors contributed to the amount of direct healthcare costs.

Table 3. Univariate and multivariate linear regressions with log direct healthcare costs per month of survival as dependent variable

\begin{tabular}{|c|c|c|c|c|}
\hline \multirow[b]{2}{*}{ Independent predictor variable } & \multicolumn{2}{|c|}{ Univariate regression, Log healthcare costs } & \multicolumn{2}{|c|}{$\begin{array}{l}\text { Multivariate regression }{ }^{a, b}, \text { Log healthcare } \\
\text { costs }\end{array}$} \\
\hline & Coefficient $(95 \% \mathrm{Cl})$ & t; df; p-value; & Coefficient $(95 \% \mathrm{Cl})$ & $\mathrm{t}$; df; p-value \\
\hline Male sex (yes/no) & $0.08(-0.02-0.18)$ & $1.65 ; 353 ; 0.100$ & $0.16(-0.06-0.25)$ & $3.25 ; 264 ; 0.001^{c}$ \\
\hline Low education, $<9$ years (yes/no) & $-0.064(-0.16-0.04)$ & $1.25 ; 347 ; 0.211$ & $-0.04(-0.14-0.05)$ & $0.89 ; 260 ; 0.374^{d}$ \\
\hline $\begin{array}{l}\text { Loneliness, sometimes or often } \\
\text { (yes/no) }\end{array}$ & $0.11(0.02-0.20)$ & $2.37 ; 338 ; 0.018$ & $0.14(0.03-0.24)$ & $2.62 ; 264 ; 0.009$ \\
\hline $\begin{array}{l}\text { Use of mobility assistive devices } \\
\text { (yes/no) }\end{array}$ & $0.08(-0.02-0.17)$ & $1.57 ; 353 ; 0.118$ & $0.03(-0.08-0.14)$ & $0.52 ; 260 ; 0.604^{d}$ \\
\hline $\begin{array}{l}\text { Lower ADL functions (EQ-5D), } \\
\text { (yes/no) }\end{array}$ & $0.04(-0.08-0.15)$ & $0.61 ; 353 ; 0.541$ & $-0.15(-0.28-(-0.02)$ & $-2.27 ; 264 ; 0.024$ \\
\hline $\begin{array}{l}\text { Pain/ Discomfort (EQ-5D), moderate } \\
\text { or extreme (yes/no) }\end{array}$ & $0.00(-0.10-0.10)$ & $0.05 ; 353 ; 0.964$ & $0.02(-0.08-0.12)$ & $0.36 ; 260 ; 0.718^{d}$ \\
\hline $\begin{array}{l}\text { Cognitive dysfunction (MMSE }<25 p \text {, } \\
\text { yes/no) }\end{array}$ & $0.03(-0.11-0.16)$ & $0.40 ; 353 ; 0.687$ & $-0.06(-0.21-0.08)$ & $-0.85 ; 260 ; 0.394^{d}$ \\
\hline $\begin{array}{l}\text { Somatic multimorbidity ( } \mathrm{n} \text { chronic } \\
\text { diseases) }\end{array}$ & $0.05(0.01-0.08)$ & $2.88 ; 353 ; 0.004$ & $0.04(0.01-0.08)$ & $2.81 ; 264 ; 0.005$ \\
\hline Presence of SSD Ever vs ND both & $0.13(0.03-0.23)$ & $2.58 ; 278 ; 0.011$ & $0.11(0.01-0.21)$ & $2.20 ; 264 ; 0.029^{e}$ \\
\hline
\end{tabular}

\footnotetext{
a Adjusted $\mathrm{R}^{2}=0.083$ for the stepwise linear regression, and $\mathrm{F}=5.88, \mathrm{df}=5,264$ for the model of five significant predictors female sex, loneliness, usual activities, somatic multimorbidity, and presence of SSD.

${ }^{b}$ The multivariate regression analyses were based on $n=280$ out of the $n=316$ sample, as all other than the categories ND both $(n=152)$ and SSD Ever $(n=128)$ were excluded listwise.

${ }^{c}$ Mean total healthcare cost per month of survival was $€ 611( \pm 593)$ for men, and $€ 500( \pm 495)$ for women, which means a $19 \%$ lower mean total healthcare cost for women.

${ }^{\mathrm{d}}$ The coefficient, $95 \% \mathrm{CI}$ and associated $\mathrm{p}$-value of the multivariate regression for this variable were taken from the first stepwise model, corresponding to an entry procedure for all the variables together. In the final stepwise backward automatic regression model this variable was actually removed as it was non-significant.

${ }^{\mathrm{e}}$ In the sensitivity analyses the p-value for this variable was 0.042 with a discount rate of $0 \%$, and 0.029 with a discount rate of $5 \%$.
}

\subsection{Discussion}

The aims of this study were two-fold: to provide a comparison between the prospective healthcare direct costs and service utilization for persons with SSD compared with nondepressive persons in a Swedish population of very old persons during a five-year period, and also to develop a model that predicts increased direct healthcare costs in very old persons. 
We found that the total direct healthcare costs for persons with SSD at either baseline or at one-year follow-up (SSD Ever) significantly exceeded those of persons with non-depression on both occasions (ND Both), with a mean total cost per month of survival 1.45 times higher for persons with SSD Ever compared to ND Both. This is in line with the few previous studies on costs of depression in the very old $(10,11)$, and also in line with studies on costs of subsyndromal depression in younger old persons $(6,7)$. The size of the difference in this study on SSD was about equal compared to studies on syndromal depression in very old persons or studies on syndromal depression in those of younger ages $(6,30)$ even though the general pattern across studies is that higher levels of depressiveness correlate to increasing direct costs, functional decline and suffering, a pattern also in accordance to a dimensional paradigm of mood conditions and disorders $(5,31)$.

Regarding our second aim - to develop a model that predicts increased direct healthcare costs in very old persons - the multivariate regression model revealed that predictors for direct healthcare costs in our study were male sex, ADL functions, loneliness, presence of SSD, and somatic multimorbidity. The findings that male sex and higher ADL functions predict increased healthcare costs contradict to previous findings $(10,14)$. A possible explanation why male sex predicted higher costs in this sample would be the higher mortality for men compared to peer women of old ages, while the switch from positive coefficient of lower ADL functions in the univariate regression to a negative coefficient in the multivariate regression might be interpreted as a result of interactions between the variables. Also the selective missing data for both female sex and lower ADL functions might contribute to these unexpected findings. Further, the findings that loneliness, presence of SSD, and somatic multimorbidity all predict higher healthcare costs are similar as in previous studies $(7,9,10$, 16) even though the explanatory power for the regression model as well as for the individual variables was small.

The mean total healthcare costs per capita in this study amounted to $€ 608( \pm 628)$ per month which (extrapolated to annual costs corresponding to $€ 7301$ or $\$ 8217$ ) were relatively high compared to similar previous studies on depression in the elderly, with a range of $\$ 900-9632$ annually $(6,11)$. A possible explanation for these comparatively high mean total costs would be that our study was on subjects of older ages and with a relatively higher degree of multimorbidity than those in other studies. Another possible explanation for variation of costs across studies and countries could of course be the different organization of mental and somatic health services. The healthcare expenditure per capita in Sweden during the study period was about $15 \%$ higher than the OECD mean, or about $50 \%$ lower than the expenditure per capita in the US, and with a slightly larger proportion of outpatient care compared to the former (32).

There have been many suggestions to explain why persons with depressiveness have higher costs in general than non-depressive persons: for example that the psychiatric symptoms themselves lead to extra treatments, that depressive symptoms are associated with the development of certain unspecific somatic symptoms, and that depressive symptoms complicate the treatment of somatic disorders, for example through non-adherence to treatment $(11,33)$. In contrast to the significant differences in direct costs, there were no significant differences between SSD Ever and ND Both in healthcare service use in terms of number of contacts, according to the register data available in this study. This is an inconsistency of our data, as the healthcare cost data is indirectly based on the healthcare service register. This inconsistency may be due to the variation of diagnoses, which was not considered in our analyses. 
Only about one per thousand of outpatient care visits was to specialized psychiatric care in our study, which was in stark contrast to the much larger cost proportion of about nine percent that specialist psychiatric care constitutes of healthcare costs to adults of all ages in Sweden (34). This agrees with previous findings that older people underuse mental health services (35). The reason why very old persons have such a small consumption of psychiatric care is not fully understood. Lack of access to psychiatric healthcare resources can be a result of depressive symptoms themselves or of disability (36), a result of barriers in the meeting with healthcare personnel (37), of ageism (38), of stigma from mental health problems, or simply due to the patients' preferences (39).

In accordance with our hypothesis the costs for SSD Ever were higher than costs for ND Both, independently of somatic multimorbidity, and presence of SSD was also a significant predictor for healthcare costs in the final multivariate regression model even though the effect size was small. However, the relationship between depression, multimorbidity and frailty has been described as complex and multidirectional, and these variables frequently coexist in very old persons (40). Somatic multimorbidity and loneliness were both significant predictors of healthcare costs as hypothesized, as was male sex. Against our hypotheses, none of the variables cognitive dysfunction, chronic pain, lower ADL functions or physical functioning predicted higher direct healthcare costs significantly in the multivariate regression. To sharpen the prediction of direct costs in depressiveness of late-life, further research is warranted, particularly as cost-effective interventions for the conditions are gradually becoming available $(39,41)$.

\subsection{Limitations}

A number of limitations of this study should be considered. Only $57 \%$ of the eligible population or $75 \%$ of baseline participants responded to the GDS measurement, and there were systematical differences between the responders and non-responders. Therefore, one has to be cautious regarding the generalizability of the results to certain subgroups of very old persons, namely females, those with adapted housing, and lower ADL functions. Compared to peers of the whole country, the responders also had significantly lower educational level $(67 \%$ with $<9$ years of education in the study, compared to only $55 \%$ in the country) but the same sex distribution. Moreover, subsyndromal depression was defined by the screening instrument of GDS-15 instead of the DSM-5 classification, which is of relevance for the validity. The DSM-5 as a gold standard matches much of the psychiatric literature better than GDS-15 in many ways, though a screening instrument has other important advantages, not least from a health economic perspective (30), and is appropriate to a dimensional perspective on affective conditions (22). In order to increase validity we classified the depressiveness of participants according to two consecutive measurements, as affective disorders vary in intensity over time. An alternative study design with more frequent measurements of depressiveness would have allowed study of the longitudinal and possibly causal relations between depressiveness and direct costs. Finally, the study builds on the Swedish healthcare system with both similarities and differences from healthcare systems of other countries, which is why extrapolating the findings to other countries should be done with caution.

\section{Conclusions}

In conclusion, this is the first study focusing on the cost-of-illness of SSD in very old persons, and we found that persons with SSD had significantly higher total direct healthcare costs per month of survival than non-depressive persons among the very old. Also, our multivariate 
regression revealed five factors - male sex, ADL functions, loneliness, presence of SSD, and somatic multimorbidity - as predictors of future direct healthcare costs, even though the effect size of the model as well as the individual predictors were small. Subsyndromal depression in late life is common and is associated with increased costs for society in addition to both functional impairment and suffering for the individuals and their families. Future research should analyze the relationships between depressiveness, multimorbidity and healthcare costs longitudinally in order to identify causal aspects and mechanisms, to better guide the allocation of resources in health policy, and to continue developing the effectiveness of interventions for depressiveness in late life. Moreover, better directed and tailored prevention and treatment for those who need it should also be developed in future studies. 


\section{References:}

1. Benjamini Y: Discovering the false discovery rate. Journal of the Royal Statistical Society: Series B (Statistical Methodology) 2010; 72:405-416

2. Mathers CD,Loncar D: Projections of global mortality and burden of disease from 2002 to 2030. PLoS medicine 2006; 3:e442

3. Ludvigsson M, Milberg A, Marcusson J, et al: Normal Aging or Depression? A Qualitative Study on the Differences Between Subsyndromal Depression and Depression in Very Old People. The Gerontologist 2015; 55:760-769

4. Lavretsky H, Kurbanyan K,Kumar A: The significance of subsyndromal depression in geriatrics. Current psychiatry reports 2004; 6:25-31

5. Meeks TW, Vahia IV, Lavretsky H, et al: A tune in "a minor" can "b major": a review of epidemiology, illness course, and public health implications of subthreshold depression in older adults. J Affect Disord 2011; 129:126-142

6. Luppa M, Sikorski C, Motzek T, et al: Health service utilization and costs of depressive symptoms in late life - a systematic review. Current pharmaceutical design 2012; 18:59365957

7. Katon WJ, Lin E, Russo J, et al: Increased medical costs of a population-based sample of depressed elderly patients. Arch Gen Psychiatry 2003; 60:897-903

8. Unutzer J, Patrick DL, Simon G, et al: Depressive symptoms and the cost of health services in HMO patients aged 65 years and older. A 4-year prospective study. JAMA 1997; 277:1618-1623

9. Bahler C, Huber CA, Brungger B, et al: Multimorbidity, health care utilization and costs in an elderly community-dwelling population: a claims data based observational study. BMC health services research $2015 ; 15: 23$

10. Luppa M, Konig HH, Heider D, et al: Direct costs associated with depressive symptoms in late life: a 4.5-year prospective study. International psychogeriatrics / IPA 2013; 25:292302

11. Bock JO, Brettschneider C, Weyerer S, et al: Excess health care costs of late-life depression - Results of the AgeMooDe study. Journal of affective disorders 2016; 199:139147

12. Bock JO, Hajek A, Weyerer S, et al: The Impact of Depressive Symptoms on Healthcare Costs in Late Life: Longitudinal Findings From the AgeMooDe Study. The American journal of geriatric psychiatry : official journal of the American Association for Geriatric Psychiatry 2017; 25:131-141

13. Leibson CL, Long KH, Ransom JE, et al: Direct medical costs and source of cost differences across the spectrum of cognitive decline: a population-based study. Alzheimer's \& dementia : the journal of the Alzheimer's Association 2015; 11:917-932

14. Reuben DB, Seeman TE, Keeler E, et al: The effect of self-reported and performancebased functional impairment on future hospital costs of community-dwelling older persons. Gerontologist 2004; 44:401-407

15. Lazkani A, Delespierre T, Bauduceau B, et al: Healthcare costs associated with elderly chronic pain patients in primary care. European journal of clinical pharmacology 2015; 71:939-947

16. Pitkala $\mathrm{KH}$, Routasalo $\mathrm{P}$, Kautiainen $\mathrm{H}$, et al: Effects of psychosocial group rehabilitation on health, use of health care services, and mortality of older persons suffering from loneliness: a randomized, controlled trial. The journals of gerontology. Series A, Biological sciences and medical sciences 2009; 64:792-800 
17. Nagga K, Dong HJ, Marcusson J, et al: Health-related factors associated with hospitalization for old people: comparisons of elderly aged 85 in a population cohort study. Archives of gerontology and geriatrics 2012; 54:391-397

18. Mossialos EW, M.; Osborn, R.; Sarnak, D. (eds): International Profiles of Health Care Systems, 2015. The Commonwealth Fund, 2016

19. Sheikh JA,Yeasavage JA: Geriatric Depression Scale (GDS): recent findings and development of a shorter version., in Clinical Gerontology: A Guide to Assessment and Intervention. Edited by Brink TL. New York, Howarth Press, 1986, pp

20. de Craen AJ, Heeren TJ,Gussekloo J: Accuracy of the 15-item geriatric depression scale (GDS-15) in a community sample of the oldest old. Int J Geriatr Psychiatry 2003; 18:63-66

21. Chachamovich E, Fleck M, Laidlaw K, et al: Impact of major depression and subsyndromal symptoms on quality of life and attitudes toward aging in an international sample of older adults. The Gerontologist 2008; 48:593-602

22. Judd LL: Dimensional paradigm of the long-term course of unipolar major depressive disorder. Depression and anxiety 2012; 29:167-171

23. Wirehn AB, Karlsson HM,Carstensen JM: Estimating disease prevalence using a population-based administrative healthcare database. Scandinavian journal of public health 2007; 35:424-431

24. Wirehn AB, Andersson A, Ostgren CJ, et al: Age-specific direct healthcare costs attributable to diabetes in a Swedish population: a register-based analysis. Diabetic medicine : a journal of the British Diabetic Association 2008; 25:732-737

25. Fortin M, Stewart M, Poitras ME, et al: A systematic review of prevalence studies on multimorbidity: toward a more uniform methodology. Annals of family medicine 2012; 10:142-151

26. Folstein MF, Folstein SE,McHugh PR: "Mini-mental state". A practical method for grading the cognitive state of patients for the clinician. Journal of psychiatric research 1975; $12: 189-198$

27. Iverson GL: Interpretation of Mini-Mental State Examination scores in communitydwelling elderly and geriatric neuropsychiatry patients. Int J Geriatr Psychiatry 1998; 13:661666

28. EuroQol G: EuroQol--a new facility for the measurement of health-related quality of life. Health policy $1990 ; 16: 199-208$

29. Park NS, Jang Y, Lee BS, et al: The mediating role of loneliness in the relation between social engagement and depressive symptoms among older Korean Americans: do men and women differ? The journals of gerontology. Series B, Psychological sciences and social sciences 2013; 68:193-201

30. Luppa M, Heinrich S, Angermeyer MC, et al: Cost-of-illness studies of depression: a systematic review. J Affect Disord 2007; 98:29-43

31. Ayuso-Mateos JL, Nuevo R, Verdes E, et al: From depressive symptoms to depressive disorders: the relevance of thresholds. The British journal of psychiatry : the journal of mental science 2010; 196:365-371

32. OECD: Health at a Glance 2011, OECD Publishing (Organisation for Economic Cooperation and Development), 2011

33. Donohue JM,Pincus HA: Reducing the societal burden of depression: a review of economic costs, quality of care and effects of treatment. PharmacoEconomics 2007; 25:7-24

34. Anell A, Glenngård A,Merkur S: Sweden: Health system review., 2012

35. Byers AL, Arean PA, Yaffe K: Low use of mental health services among older

Americans with mood and anxiety disorders. Psychiatric services 2012; 63:66-72

36. Hoeft TJ, Hinton L, Liu J, et al: Directions for Effectiveness Research to Improve Health Services for Late-Life Depression in the United States. The American journal of geriatric 
psychiatry : official journal of the American Association for Geriatric Psychiatry 2016; 24:1830

37. Sussman T, Yaffe M, McCusker J, et al: Improving the management of late-life depression in primary care: barriers and facilitators. Depression research and treatment 2011; 2011:326307

38. Schroyen S, Adam S, Jerusalem G, et al: Ageism and its clinical impact in oncogeriatry: state of knowledge and therapeutic leads. Clinical interventions in aging 2015; 10:117-125 39. Hall CA,Reynolds-III CF: Late-life depression in the primary care setting: challenges, collaborative care, and prevention. Maturitas 2014; 79:147-152

40. Vaughan L, Corbin AL,Goveas JS: Depression and frailty in later life: a systematic review. Clin Interv Aging 2015; 10:1947-1958

41. Jacob V, Chattopadhyay SK, Sipe TA, et al: Economics of collaborative care for management of depressive disorders: a community guide systematic review. American journal of preventive medicine 2012; 42:539-549 